\title{
Characteristics of Age-Friendly Bus Information
}

\author{
Kieran Broome, University of the Sunshine Coast \\ Linda Worrall and Jennifer Fleming, The University of Queensland \\ Duncan Boldy, Curtin University of Technology
}

\begin{abstract}
Bus information is an important element to consider when developing and implementing age-friendly bus systems. Little is known regarding the bus information needs and preferences of older people. This study aims to illuminate characteristics of age-friendly bus information. Participant observations with stimulated recall interviews ( $n=40)$ were used to identify older peoples' (age 60 and over) perspectives on bus information. The data were analyzed using qualitative content analysis. A printed information location checklist also was conducted. Categorical analysis identified that older people used a variety of information sources including printed information, telephone, Internet, bus drivers, word of mouth, and experience. Positive and negative characteristics of each source were identified. Older people also required a range of levels of information complexity. Popular locations for sourcing printed information included post offices, news agents, tourist information centers, and libraries. Transport providers and policy makers should consider the needs and preferences of older people when providing bus information. Effective information provision requires a range of media, covering a broad spectrum of information complexity and through a variety of locations.
\end{abstract}




\section{Introduction}

With aging populations in many western countries, there is an imperative to provide transport services that are accessible for older people. In Australia, for instance, the proportion of older people is expected to at least double in the first half of this century (Alsnih and Hensher 2003). Older people have a greater risk of difficulty catching buses and other forms of public transport, despite an increased reliance on public transport for community mobility (Glasgow and Blakely 2000; Dent et al. 1999; Davey 2007). In a study involving 620 older Australians (age 75 and over), a third reported difficulty using public transport (Dent et al. 1999). Fifteen percent of the sample had difficulty with both private and public transport and had no access to transport assistance.

Using buses is a complex process requiring multiple stages such as planning the trip, moving to and from the bus stop, getting on and off the bus, and interacting with bus drivers and other passengers. Significant attention has been given to researching low floor buses and other physical accessibility innovations, with relatively little consideration of other aspects of the bus system such as information and communication needs (Ashton et al. 2008). Finding, understanding, and processing information to plan a bus journey is a key step to using a bus system that has been relatively unexplored in the literature. The quality of bus information has been identified by older people as a potential barrier to their ability to use buses (Department for Transport UK 2001; Broome et al. 2009). Providing appropriate information and training has been identified as a core priority in providing an age-friendly bus system (Broome, Worrall et al. 2010). Indeed, older people have specific requirements for information that differ from the needs of younger adults (Broome, Nalder et al. 2010). Existing systems that may be designed without the explicit needs of older people in mind may not be appropriate.

It has been noted that the current generation of older bus users has a preference for printed materials over online or telephone information (Environment Victoria 2004; Fiedler 2007). Various recommendations exist for the provision of usable and accessible printed materials regarding font size (minimum of 10 pt, 14 pt recommended), font type (sans serif), color contrast (preferably black on white), and the need for information to be clear and concise (Environment Victoria 2004; Fiedler 2007; Shaheen and Rodier 2006; Texas Transportation Institute and Nustats International 1999). These recommendations, however, rarely are reported alongside evidence-based justifications. The most comprehensive sources (Texas Transportation Institute and Nustats International 1999) also are not age-specific. It is likely 
that the recommendations simply have been drawn from disability literature, given their similarities. There are many potential shortcomings when applying disability standards to older people, as disability standards rarely take into account the cognitive, social, and generation-specific needs of older people (Harrison 2004).

There also are discernible shortcomings in the literature related to the provision of bus information to older people. The provision of information involves more than text and readability of written timetables. General guidelines for information provision for older people (not specific to bus information) have been suggested, including providing appropriate, clear and concise information and using a variety of sources for dissemination (Everingham et al. 2009). The role that the Internet and telephone services play for some older people is relatively uncharted, although they may be increasingly applicable with the growth of smart phones. Bus drivers are one of the most available sources of information during a bus journey. Despite this, the friendliness and helpfulness of bus drivers, the second highest priority for older people (Broome, Worrall et al. 2010), also has attracted minimal research attention. Similarly, the availability of printed information attached to bus stops signs (as opposed to printed timetables) has received little consideration. In regards to printed timetables, a review of the literature found no research that recommends where older people would prefer to source printed timetables.

Given these gaps in the research, a mixed-methodology approach has been adopted in the present study to further our understanding in a number of areas of bus information provision for older people. The aims of the current study are to 1) elicit experiences of older people using various forms of information, 2) elucidate the specific information needs of older people, and 3) determine sources of printed information used and preferred by older people.

\section{Methodology}

Multiple methods were used to establish the bus information needs of older people. The study used qualitative analysis of stimulated recall interviews (associated with an actual bus trip) to garner older peoples' perspectives on bus information. A quantitative analysis of the stimulated recall interviews is covered in a previous paper (Broome, Worrall et al. 2010). This information was supplemented by a checklist to establish known and preferred sources of printed information. 


\section{Sampling}

Volunteer sampling and maximum variation sampling were used to attain a sample of 40 older people age 60 and over. The sample targeted in this study is drawn from a larger volunteer sample from a previous study (Broome, Worrall et al. 2010). Two sample sites from Queensland, Australia, were used. Participants from Hervey Bay provided perspectives on a regional bus service, and participants from Brisbane represented users of a metropolitan bus service. The two sites were selected to provide divergent perspectives, as transport disadvantage is known to differ between metropolitan and more rural contexts (Glasgow and Blakely 2000).

To minimize self-selection bias, maximum variation sampling (to reflect diversity) was used to select 40 participants from a volunteer sample of 227 older people who took part in the larger research study (Broome, Worrall et al. 2010). Maximum variety aims to attain a broad spectrum of perspectives by purposively selecting participants who reflect various combinations of parameters. Parameters used in this study were frequency of bus use, difficulty of bus use, and sample site. Each of the 40 participants took part in a bus trip followed by a stimulated recall interview. Of these participants, 33 also completed the checklist on printed information sources. Eligibility criteria for the study were community-dwelling, age 60 or over, and with sufficient cognitive and language skills to complete the interview. No incentives were provided for participation in the study.

\section{Outcomes Measures}

All participants, as part of the previous study (Broome, Worrall et al. 2010), completed an initial questionnaire including demographics and car use, as well as frequency (3-pt scale) and ease (10-pt scale) of bus use. Higher scores represented greater ease of bus use. The previous study used the nominal group technique to identify and prioritize barriers and facilitators to bus use for older people. The importance of information accessibility was identified at this stage. Following selection from the larger sample, the 40 participants were invited to take part in observations of their bus use and stimulated recall interviews. Stimulated recall interviews are used to elicit participants' recalled experience of actual events or situations (Davidson et al. 2006; Skovdahl et al. 2004). Stimulated recall interviews uncover the subjective experience of participants in relation to observed events. The stimulus material may be, for example, a video, audio recording, or verbal prompts related to a recent activity. In this case, the stimulus was a return bus trip. A researcher accompanied each participant on a bus trip of the participant's 
choosing. Prior to the bus trip, the stimulated recall interview was initiated using a semi-structured interview to elicit participants' perspectives on planning the bus trip. Participants were asked to identify what helped (facilitators) or hindered (barriers) planning the bus trip. Following the bus trip, the stimulated recall interview was continued with stimuli including phases of the bus trip, such as getting to and from the bus stop, embarking and disembarking the vehicle (e.g., "then you stepped on to the bus"), and moving on and around the vehicle. Participants were asked what helped or made it more difficult to catch the bus at each phase. Additional prompts based on observations by the researcher (e.g., "then a person on the bus moved off a seat for you to sit down") also were used. Interviews averaged approximately 105 minutes in duration. Each interview was audio recorded and transcribed.

Participants also completed a checklist on sources of printed information and were asked where they knew timetables were available or where they thought timetables should be available. The checklist was completed at the end of the interview. Stimulus questions included, "You have mentioned places where you have got timetables. Is there anywhere else you know you could get a timetable?", "Is there anywhere else you think would be a good place for you, an easy place to pick up a timetable?" and "What is it about the place that makes it good, that would make you think it is there or should be there?" Prompt locations included timetables on the bus and at the library, the council, news agencies, post offices, community groups/venues, bus depot/booking centers, and tourist information centers. Participants were encouraged to mention other applicable locations. Comments relating to the locations-for example, how easy they were to get to-also were recorded.

\section{Data Analysis}

Demographics were described using descriptive statistics. Qualitative content analysis (Graneheim and Lundman 2004) was used to identify categories and themes from the stimulated recall interviews. Salient comments related to bus information were identified within the transcripts. These comments were organized into subcategories, with subcategories then grouped under overarching categories. A review of the data as a whole, as well as categories and subcategories, was used to uncover themes related to bus information that permeated the transcripts. A peer review process, where the qualitative content analysis was reviewed by a second researcher, was used to improve the rigor of data analysis. In the peer 
review process, the second researcher was provided with the raw qualitative data relating to bus information and coded these into categories. Where discrepancies in categorization existed, discussion continued until a consensus was reached. When consensus could not be reached, a third researcher was available to mediate categorization, but was not required. Supplementary data from the checklist were analyzed using descriptive statistics to highlight frequently known and frequently preferred sources of printed timetables.

\section{Findings}

\section{Demographics}

Participant characteristics are shown in Table 1. The sample represented a diversity of transport situations and self-rated ease of bus use. There were more females than males who took part in the study, which may limit the generalizability of findings.

\section{Table 1. Participant Characteristics}

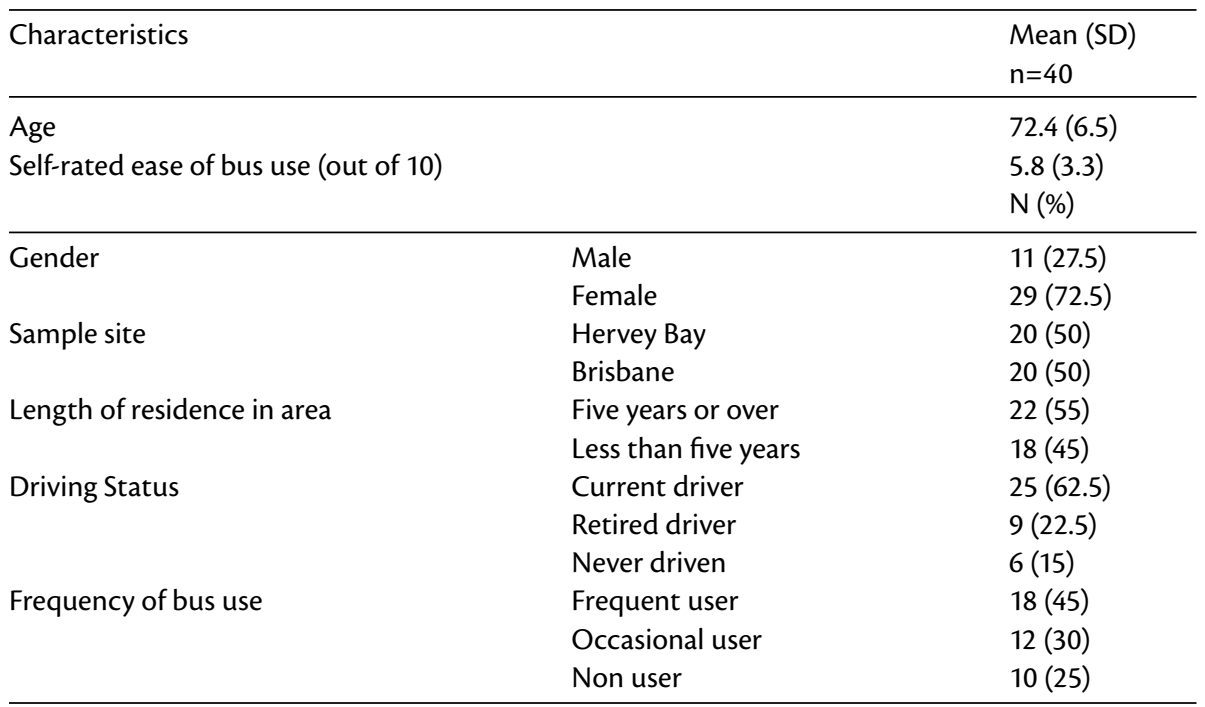

\section{Qualitative Content Analysis}

An outline of the categories and subcategories is shown in Figure 1 and described in more detail in the following sections. The comments relate to barriers and facilitators to using bus information identified by older people. 


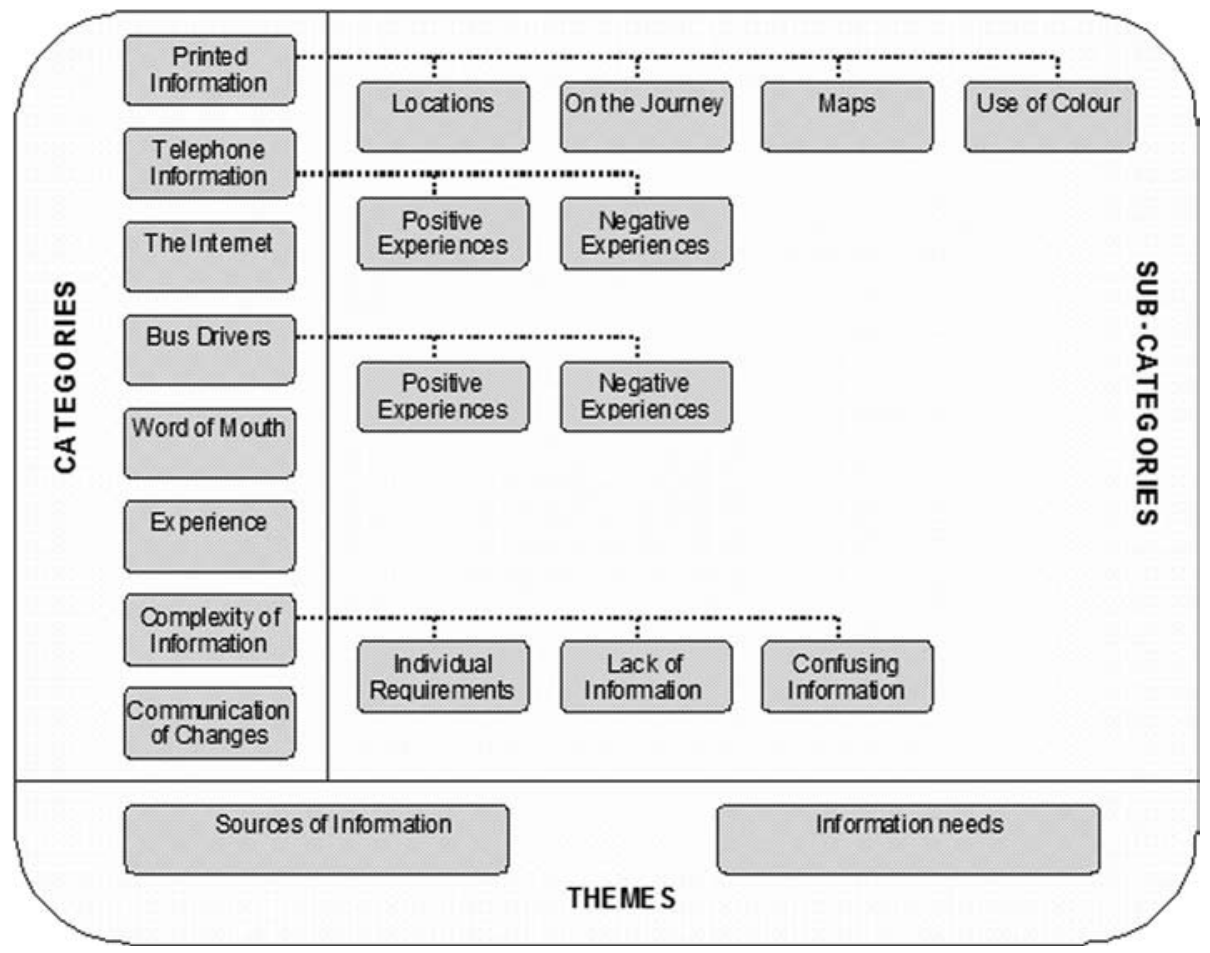

\section{Figure 1. Categories and themes relating to barriers and facilitators to bus use for older people}

Categories of bus information included printed information (both printed timetables and at the bus stop), word-of-mouth (friends, family, neighbours, strangers), bus drivers, telephone services (bus company or information line), and the Internet. Some participants did not use information sources, and these were categorized as "experience" (e.g., previous experience, just turned up, previously saw that a bus with a destination sign had come past). Other categories included the complexity of information required and communication of changes to the bus system.

\section{Printed Information}

Printed information was the most common source of information and attracted the most comment. This included both printed timetables that were carried on the person as well as information at the bus stops. The ability to source printed timetables as a prerequisite to using buses was identified as a barrier by some participants. Often timetables were difficult to access. As one participant stated: 
Just the non-availability of schedules, [I] found that frustrating. I guess they work on the premise that the people that use the buses are frequent travelers and they have the schedules memorized. The lady at the corner knew exactly when her bus was due along the esplanade the other day and on Saturday.

One new bus user noted that when she was new to the area and she did not know where to look for printed timetables.

The provision and locations of printed timetables needed to be intuitive to new buses users. As one user noted, "You've got to think in the customer's mind, not your own. So where would you go, you go to a new town ... go to Centro. Or go into a news agent or one of the tourist shops.... That's where l'd go, but a lot of people don't think that way."

In many cases, the sources of printed timetables were not intuitive, as described by one participant: "That's what sort of got me, they drop off ... [their schedules] to hotels and motels in the bay.... They don't ... put them into banks." One site, Hervey Bay, had initiated an effective approach of using a letterbox drop, which overcame this issue of finding printed timetables.

Often, participants also needed to access information during the journey or used the information at bus stops rather than planning ahead. In this situation, portable printed timetables or information attached to the bus stop sign became invaluable. A number of participants commented on the ability to have pocket-sized folded timetables, highlighting the need for small and durable timetables. Other participants preferred information at bus stops. Information at bus stops needed to be consistent across stops, as was noted: "There's not information at the stops here, not all the stops have got information.... I think all stops should have a timetable."

With respect to the content of the timetable, the importance of the map was predominant. The majority of participants who used printed information relied on the map:

Definitely those maps were essential, substantial. The way they set them out, separating the routes out. It leaves no doubt in a person's mind where the pickup points are and how they move around, and that's very important.

The map was often the first point of reference to decide whether a bus route was applicable for the person's journey. One participant, while planning her trip, dem- 
onstrated increased understanding of her journey after referring to the map. Maps were not included on timetables in all jurisdictions:

Getting that timetable made all the difference, and being able to see where the buses actually went. Having those pictures of the route on it ... I think it's an excellent timetable, much better than the ones we had in the city. They were just a sort of a typed sheet and that was about it.

When designing the map itself, including each route and marking the direction of routes with arrows was valuable. Also, maps have the potential to communicate more than just routes. Where relevant they can give important information on zones related to ticket prices:

I find the ones we have adequate because they have a map. They show you the zones so you can follow where you're going. But I picked up a timetable I was using the other day and it didn't have that on. And I said to my husband, "Isn't that strange, we don't know what zone we're in."

Color is an important facilitator in timetable design to orientate the reader to the map and routes. Many participants discussed the use of color in a positive manner, often using color to link timetables to maps. Consideration should be given to ensuring high contrast between the color and the background, as well as a preference for using matte paper to avoid glare. Use of color should be accompanied by a key to illustrate the meaning of each color. On the subject of color, one participant drew parallels with the London Tube system, where the colored route map has become iconic:

I think having the different colored routes [helps], I mean, we were struck on the tube in London, you know, the routes were different colored and you knew what routes you needed. It makes it so much easier to look up.

\section{Telephone Information}

Telephone information was also a popular source for participants. Depending on the type of phone system and the quality of staff, some participants had very good experiences with telephone information. Two participants described very positive experiences, as one mentioned:

I found that very helpful. I found the staff helpful. I was enquiring particularly just a couple of weeks ago to visit my brother and I didn't know how to get there. They were very helpful, they gave the bus stop to wait at, they 
gave me all the information that I required, and I thought that was very helpful.

In contrast, some participants had negative experiences with telephone information. One participant noted that "I don't do many calls on the phone, only what I have to, because l've got a deaf phone, and it's very hard sometimes even hearing the deaf phone." This highlighted not only the need for multiple sources of information to cater for sensory impairments, but also the potential role for effective communication strategies used by staff. Automated telephone systems also were negatively perceived. One participant called the automated system "a little bit of a pest ... because you're not actually talking to a person at times and they don't always know what l've said to that machine." She went on to describe an illustrative situation where "I had to repeat myself three times to answer the question, 'Did you say so and so' and I said, 'No! So and so' and that went on for a bit and then I think probably they did put me on to somebody."

\section{The Internet}

While many participants did not use the Internet to find bus information, a few did. Many participants did not use the Internet at all. One participant stated, concerning computers, "The fact that my life doesn't seem to need one. At nearly 81, I might find it a bit difficult. I have friends who have trouble with the, uh, machines." Some had access to the Internet but did not use it as a source of bus information. As one participant described, he would "much rather use the little paper one, [it] wouldn't occur to me to go on the web, it's just there, it's handy." This lack of familiarity with computers and the Internet is likely to change as successive generations age. Therefore, the provision of accessible bus information via the Internet should become part of a long-term strategy for age-friendly information provision.

Familiarity with the Internet also may be influenced by the local demographic and may differ in other areas of the world where Internet use by older people may be more common. Additional factors affecting Internet use, include changes in vision, prompted one participant to mention:

I found that out from the Internet, and then I found it a bit difficult to read it on the computer. My eyes are getting old. But I worked out an itinerary. I thought, l'd better go and get a timetable. So I went and got a [printed] timetable then so that I could just check that what I read on the computer was up to date. 


\section{Bus Drivers}

Bus drivers were also a commonly consulted and very convenient source of bus information. As one participant stated, "The bus drivers were helpful with their information. They'd say, well, where do you want to go? And l'd tell them, and they'd give me the information. All you've got to do is open your mouth and ask the drivers or get on the phone and ring the bus service." In many cases, this information was in addition to using timetables for trip planning. Bus drivers often knew specific information that was not in timetables-for example, how the bus system worked, where specific locations were-and could assist when timetables were not available or were outdated.

The effectiveness of bus drivers as a source of information was strongly influenced by their friendliness, helpfulness, and knowledge. As one participant stated, "I've found bus drivers at all levels. The two bus drivers [today] were very good. I mean they knew where we wanted to go and they knew what we were about and that's I think the role of the bus driver-to get a passenger to and from the point of embarking to the point of disembarking." Many bus drivers, especially in regional Hervey Bay, were very friendly and helpful. A positive experience recounted by one participant was that:

They'll say, well, I want to go to such and such, and then the bus driver will say the closest, and then he'll call out whoever wanted to go to such and such a place, this is where you get off. And then as they get off, they'll point and say, then you go up that street. And they're very helpful that way.

In contrast, some older people also had negative experiences with bus drivers. "There's one grumpy one I don't like. I thought, I won't ask him again (laughed)."

\section{Word-of-Mouth}

It was not uncommon for participants to also use less formal sources of information, such as word of mouth. Other service providers (such as shop assistants), neighbours, and strangers at the bus stop were common sources of information. One participant elaborated on her experience, saying that, "I'd walk down and catch the bus and listen to people talking on the bus; if they're talking about something, your ears pick up. So the bus goes from here to there, and all this sort of thing, but times were more of a problem because I didn't know how many buses we have a day or anything." Word-of-mouth often could provide additional information not available in timetables, such as recommendations from experience on 
the best connections to take. At times, word-of-mouth was limited: "And I think it's pretty fair to say that most people that don't use buses don't talk buses."

\section{Experience}

Some participants did not use any sources of information to plan the trip, as they had extensive experience using buses and were already familiar with routes, systems and timetables. From experience, others have confidence that they do not need to plan the trip and can wait for buses at stops that they already know. One participant stated, "As I go to the shops. I see the bus stop. I can stop and read the number of which bus it is and the route is drawn there on the bus stop sign at the shopping center."

\section{Complexity of Information Required}

Participants reported a wide range of depth of information required that were both barriers and facilitators. For some, information requirements were simple, for example, "Well, they gave me the bus routes, the times, and the connections, which is basically all I needed to get there." Others performed more extensive planning, with one participant stating;

Mostly before I go, I know when I'm going and when I'm coming home, in which case I know which bus, and I try to work out before I go, which bus is going to be the most convenient to come home on. If you don't do that, you're going to have to wait an extra hour, very simple. Saturdays are really the only day that I can't do that because there's not as many buses, so I've got to wait until 11 o'clock to after 12 to get a bus, but I usually get one at Centro.

In many cases, the information provided, either on printed timetables or via the Internet, was insufficient. In the simplest terms, one participant said, "I don't think there's enough information yet to tell me when I can leave this house and catch a bus, what time to catch a bus." Specific shortcomings include lack of details in roads and maps, as well as lack of information on ticketing. Two participants relayed their experiences of lacking information: one found that the map did not indicate a major street near her; the other found that the Internet source did not have sufficient information to work out fares and ticket types available.

It can be a perpetual challenge for transport operators to provide information that is both detailed and concise and meets standards in text size. This dilemma often requires a suite of publications, including both a network route map (to assist bus users to select appropriate routes) and separate timetables for each route. In 
some cases, the information provided was confusing or could have benefited from greater clarity. As one participant described, "It needs to be clearer, and I think it would be better if all the buses did the same thing; some do one thing, others another; when you get on, you have no idea." Another stated, "This later addition where they give the times throughout the day is a little easier, rather than when you had to add you half hours or quarter hours."

\section{Communicating Changes to the Bus System}

Unexpected changes to the bus system were barriers to using buses raised by a number of participants. Not all experiences were negative. In one positive example, the council that runs the local bus service was proactive. As a participant states, "Yes, it was in our local papers. It was advertised, and we had been informed that we would be getting the bus by the local council."

\section{Themes}

Two specific themes emerged from the qualitative content analysis. The first related to multiple sources of information. The participants who were interviewed accessed a wide range of information sources, including printed information, telephone information, the Internet, bus drivers, word-of-mouth, and experience. Some participants used only one source of information, while others used multiple sources. Therefore, transport providers should provide information through all forms of media and at many different sources. The source of information was frequently based on personal preferences. Sources of information not only are influenced by participants' preferences, but also can be limited by changes associated with aging (such as a visual impairment) or geographic factors (such as difficulty travelling to locations where printed timetable can be found). These findings are aligned to previous findings from other age-friendly literature focusing on supermarkets, GPs, financial planners, and tourism operators, which identified that older people used a variety of information sources, but commonly had a preference for printed information (Pettigrew et al. 2002).

The second overarching theme was that there was individual variation in the information needs of each participant. Some were experienced users and required only bus times. Others were new to the system and required additional background information on how the system works or how fares are structured. While there is variation in the type and depth of information that older people are seeking, there are core aspects or "questions" from the user's side, such as "How do I get to the bus stop?", “When will it come to my bus stop?", "Will it take me to where I need to go?", and "How much will it cost me?" As one participant aptly put, "You've got 
to think in the customer's mind, not your own." These findings also are aligned to previous literature that identified that older people may be served best by multiple levels of complexity of information; for example, some required limited information focused on the present situation while others preferred detailed information (Pettigrew et al. 2002).

\section{Printed Information Location Checklist}

In additional to completing the participant observations with stimulated recall interview, 33 of the participants completed the checklist on sources of printed timetables. The most common places that participants knew timetables were kept included the library (11), shopping centers (10), on the bus (9), from the council (9), at bus depots/interchanges, (7) and at tourist information centers (5). As no single location was listed by more than a third of participants, this represents a relatively low general awareness of where timetables are available. The most common places that participants thought it would be a good place to keep timetables included the post office (24), news agents (17), tourist information centers (13), libraries (13), shopping centers (9), councils (8), on the bus (8), community centers/ groups (8), and bus depots/interchanges (7). As can be seen, there is a discrepancy between where participants knew timetables were kept and where they preferred timetables to be located.

The most consistent comments regarding barriers to accessing printed information locations were that libraries and councils were often out of the way or not frequently accessed. As one participant mentioned, "You have to catch a bus to get to the library." In contrast, the post office and shopping centers were regularly frequented by older people.

\section{Discussion and Conclusion}

The results of the qualitative content analysis and the checklist neither support nor refute the previous literature on bus information that focused on fonts, contrast, and other parameters of printed materials. The participants rarely commented on these aspects and focused more on aspects not mentioned in previous literature, namely the sources and qualities of bus information. The themes fit in well with the considerations suggested (Everingham et al. 2009) for the general provision of information in age-friendly communities. The positive experiences associated with telephone information and bus drivers implicate these media as important 
aspects of a comprehensive suite of bus information sources, while the negative experiences suggest potential areas for improvement. Transport providers should reconsider their current delivery of information and whether it meets the needs and preferences of older people in terms of sources, quality and depth.

As a result of this study, the following recommendations should be an initial guide for transport providers and policy makers when designing bus information suitable for older people:

1. Transport providers should continue to use multiple media in their communication plans, including printed timetables, timetables at bus stops, telephone information lines, and Internet sources.

2. Printed timetables should be designed using clear vibrant colors with high contrast and a white background.

3. Printed timetables should include clearly marked maps and, where possible, have a separate map for each route.

4. Printed timetables should be distributed to post offices, news agents, tourist information centers, libraries, shopping centers, councils, carried on the bus, community centers/groups, and bus depots/interchanges, and in smaller jurisdictions where there is greater cost-effectiveness, a letterbox drop might be used.

5. Printed information should be available at all bus stops.

6. The effectiveness of bus drivers as information providers should be enhanced, for example, through communication training and/or agefriendliness training or through the recruitment of bus drivers with effective communication skills.

7. Telephone information should be in person or, where possible, there should be an option to go directly to an operator.

8. Similar to bus drivers, training or recruitment processes also should be applied to bus information telephone information providers to enhance their age-friendliness.

9. Improving Internet information should be part of the medium- to long-term strategy for assisting older people.

10. Changes to the bus system should be communicated through various modes, including, for example, advertising, notices at bus stops, and bus drivers.

The findings from this study extend on the existing literature, specifically proposing recommendations for providing age-friendly bus information based on older people's preferences. However, this study also experienced a number of limitations due to the design of the study. The study focuses on a limited sample, drawn from 
one country. This may lead to peculiarities in the findings, such as the limited mention of Internet use and no mention of smart phones, within this study. Therefore, the study should be replicated in other jurisdictions to increase generalizability. Additionally, while qualitative research is beneficial for exploring a phenomenon when little or no knowledge exists on the topic, such as age-friendly bus information, it is prudent to conduct subsequent quantitative analyses to validate hypotheses raised and improve the generalizability of the data. A quantitative analysis also may allude to the relative importance of each information source and quantify the difference between the metropolitan and non-metropolitan samples used in this study, which could not be obtained in this study. Once the hypotheses have been explored, the next logical step is to evaluate the impact of implementing these recommendations on ease of trip planning for older people, as well as overall bus use, satisfaction, and community participation outcomes for older people.

Prior to this study, there was a dearth of published literature about the bus information preferences of older people. This study suggests that older people access a variety of information sources and require a range of levels of complexity regarding information. By catering to the needs and preferences of older people, it is likely that the barriers to bus use will be overcome or at least minimized and older people will have a greater opportunity to use transport later in life.

\section{Acknowledgments}

This study forms part of a project supported by the Australian Research Council, Queensland Transport, and the Queensland Department of Communities, which aims to establish processes for creating, implementing, and evaluating age-friendly guidelines using the case study of public buses.

\section{References}

Alsnih, R., and D. Hensher. 2003. The mobility and accessibility expectations of seniors in an aging population. Transportation Research Part A 37: 903-916.

Ashton, C., N. Aziz, C. Barwood, R. French, E. Savina, and L. Worrall. 2008. Communicatively accessible public transport for people with aphasia: A pilot study. Aphasiology 22: 305-320. 
Broome, K., K. McKenna, J. Fleming, and L. Worrall. 2009. Bus use and older people: A literature review applying the person-environment-occupation model in macro practice." Scandinavian Journal of Occupational Therapy 16: 3-12.

Broome, K., E. Nalder, L. Worrall, and D. Boldy. 2010. Age-friendly buses? A comparison of reported barriers and facilitators to bus use for younger and older adults. Australasian Journal on Ageing 29: 33-8.

Broome, K., L. Worrall, K. McKenna, and D. Boldy. 2010. Priorities for an age-friendly bus system." Canadian Journal on Aging 29: 435-44.

Davey, J. A. 2007. Older people and transport: Coping without a car. Ageing \& Society 27: 49-65.

Davidson, B., L. Worrall, and L. Hickson. 2006. Social Communication in older age: Lessons from people with aphasia. Topics in Stroke Rehabilitation 13: 1-13.

Dent, O. F., G. A. Broe, H. Creasey, L. M. Waite, J. S. Cullen, and G. A. Grayson. 1999. Transportation needs of community-living older people in Sydney. Australasian Journal on Ageing 18: 186-190.

Department for Transport (UK). 2007. Older people: Their transport needs and requirements-Main report 2001. Accessed March 20, 2007. http://www.dft. gov.uk/pgr/inclusion/older/.

Environment Victoria. 2004. Getting about without a car: Guidelines for promoting healthy transport to older people. Accessed September 6, 2006. www.envict. org.au.

Everingham, J., A. Petriwskyj, J. Warburton, M. Cuthill, and H. Bartlett. 2009. Information provision for an age-friendly community. Ageing International 34: 79-98.

Fiedler, M. 2007. Older people and public transport: Challenges and chances of an aging society. Köln: Rupprecht Consult.

Glasgow, N., and R. M. Blakely. 2000. Older nonmetropolitan residents' evaluations of their transportation arrangements. Journal of Applied Gerontology 19: 95-116.

Graneheim, U. H., and B. Lundman. 2004. Qualitative content analysis in nursing research: Concepts, procedures and measures to achieve trustworthiness. Nurse Education Today 24: 105-112. 
Harrison, M. 2004. Defining housing quality and environment: disability, standards and social factors. Housing Studies 19: 691-708.

Pettigrew, S., K. Mizerski, R. Donovan, A. Leutero, F. Lobo, and J. Carlsen. 2002. The age friendly guidelines project. Perth: Positive Ageing Foundation of Australia.

Shaheen, S. A., and C. J. Rodier. 2007. Video transit training for older travelers: A case study of the Rossmoor Senior Adult Community, California. Accessed April 11, 2007. http://pubs.its.ucdavis.edu/.

Skovdahl, K., A. L. Kihlgren, and M. Kihlgren. 2004. Dementia and aggressiveness: Stimulated recall interviews with caregivers after video-recorded interactions. Journal of Clinical Nursing 13: 505-525.

Texas Transportation Institute and Nustats International. 1999. Passenger information services: A guidebook for transit systems. In Transit Cooperative Research Program, edited by Transport Research Board. Washington D.C.: National Academy Press.

\section{About the Authors}

Dr. Kieran Broome (KBroome@usc.edu.au) is a Lecturer in Occupational Therapy at the University of the Sunshine Coast. His doctoral study explored transport disability for older people, focusing on bus use. Concurrently, he also works clinically as an Occupational Therapist, including working with older people facing difficulties using transport.

Professor Linda Worrall (I.worrall@uq.edu.au) was a founding director of the Communication Disability in Ageing Research Centre (now the Communication Disability Centre) within the School of Health and Rehabilitation Sciences at The University of Queensland. She has published more than 180 articles on the importance of communication to successful aging, communication in aged care facilities, and communication disabilities (including hearing impairment and aphasia) associated with aging.

Dr. Jennifer Fleming (j.fleming@uq.edu.au) is an Associate Professor in Occupational Therapy and holds a conjoint research appointment with the University of Queensland School of Health and Rehabilitation Sciences and the Princess Alexandra Hospital in Brisbane, Australia. Her research is in the area of disability following acquired neurological disability, especially in relation to cognitive rehabilitation 
and community integration. She is a former Menzies Scholar and has published her work in approximately 100 journal articles and book chapters.

Dr. DunCan Boldy (d.boldy@curtin.edu.au) is a Professor in the Faculty of Health Sciences at Curtin University in Perth, Western Australia. He has a doctorate in social policy and has worked in universities in Australia, the UK and the U.S. He has a particular interest in issues related to aging and older people and many of his more than 150 refereed publications relate to this area. 